\title{
p47phox, the phagocyte NADPH oxidase/NOX2 organizer: structure, phosphorylation and implication in diseases
}

\author{
Jamel El-Benna ${ }^{1,3}$, Pham My-Chan Dang ${ }^{1}$, \\ Marie-Anne Gougerot-Pocidalo, ${ }^{1,2}$ \\ Jean-Claude Marie ${ }^{1}$ and Françoise Braut-Boucher ${ }^{1}$ \\ ${ }^{1}$ INSERM, U773, CRB3; Université Paris 7 Denis Diderot \\ Faculté de Médecine, site Bichat \\ Paris, F-75018, France \\ ${ }^{2}$ AP-HP, Centre Hospitalier Universitaire Xavier Bichat \\ CIB Phenogen, Paris F-75018, France \\ ${ }^{3}$ Corresponding author: Tel, 33-1-57-27-77-23; \\ Fax, 33-1-57-27-74-61; E-mail, jamel.elbenna @ inserm.fr \\ DOI 10.3858/emm.2009.41.4.058
}

\section{Accepted 13 April 2009}

Abbreviations: AIR, auto-inhibitory region; CGD, chronic granulomatous disease; NCF1, neutrophil cytosolic factor 1; NOX, NADPH oxidase; phox, phagocyte oxidase; PRR, proline rich region; PX, phox homology domain; ROS, reactive oxygen species; $\mathrm{SH} 3$, src homology 3 domain

\begin{abstract}
Phagocytes such as neutrophils play a vital role in host defense against microbial pathogens. The anti-microbial function of neutrophils is based on the production of superoxide anion $\left(\mathrm{O}_{2}^{*}\right)$, which generates other microbicidal reactive oxygen species (ROS) and release of antimicrobial peptides and proteins. The enzyme responsible for $\mathrm{O}_{2}^{--}$production is called the NADPH oxidase or respiratory burst oxidase. This multicomponent enzyme system is composed of two transmembrane proteins (p22phox and gp91phox, also called NOX2, which together form the cytochrome $b_{558}$ ) and four cytosolic proteins (p47phox, p67phox, p40phox and a GTPase Rac1 or Rac2), which assemble at membrane sites upon cell activation. NADPH oxidase activation in phagocytes can be induced by a large number of soluble and particulate agents. This process is dependent on the phosphorylation of the cytosolic protein p47phox. p47phox is a 390 amino acids protein with several functional domains: one phox homology (PX) domain, two src homology 3 (SH3) domains, an auto-inhibitory region (AIR), a proline rich domain (PRR) and has several phosphorylated sites located between Ser303 and Ser379. In this review, we will describe the structure of p47phox, its phosphor-
\end{abstract}

\author{
ylation and discuss how these events regulate NADPH \\ oxidase activation.
}

Keywords: CYBB protein, human; NADPH oxidase; neutrophil cytosolic factor 1; neutrophils; phosphorylation; reactive oxygen species; review

\section{Introduction}

Phagocytes such as polymorphonuclear neutrophils, eosinophils, monocytes and macrophages constitute one of the most powerful means of host defense against bacteria and fungi (Segal, 2005; Nathan, 2006). Upon infection and inflammation, neutrophils migrate towards the infection site attracted by chemoattractants such as the complement fraction $\mathrm{C} 5 \mathrm{a}$, the $\mathrm{N}$-formyl-methionyl-leucylphenylalanine (fMLF) peptide, interleukin 8 (IL-8), platelet activating factor (PAF) or leukotriene B4 (LTB4). At the infection site, neutrophils recognize and engulf the pathogen and activate the release into the vacuole of antibacterial peptides, proteases and reactive oxygen species (ROS) (i.e., superoxide anion $\left(\mathrm{O}_{2}^{\circ-}\right)$, hydrogen peroxide $\left(\mathrm{H}_{2} \mathrm{O}_{2}\right)$, hydroxyl radical $\left(\mathrm{OH}^{\bullet}\right)$ and hypochlorous acid $(\mathrm{HOCl}))$, which together contribute to death and destruction of the bacteria (Babior, 1984; Hampton et al., 1998). ROS are produced by phagocytes in a powerful "oxidative burst", characterized by a rapid, cyanide-insensitive increase in oxygen uptake, an increase in glucose consumption and abrupt $\mathrm{ROS}$ release. The enzyme responsible for $\mathrm{O}_{2}^{--}$production is the multicomponent NADPH oxidase or respiratory burst oxidase (Babior, 1999; El Benna et al., 2005). The phagocyte NADPH oxidase and ROS production play a key role in host defense against microbial pathogens as illustrated by a human genetic disorder called chronic granulomatous disease (CGD), which is associated with life-threatening bacterial and fungal infections and is characterized by an absence of ROS production due to a deficiency in one of the components of the NADPH oxidase (Meischl and Roos, 1998; Kannengiesser et al., 2008).

The phagocyte NADPH oxidase consists of several proteins that are separated between membranes and cytosol in resting cells (Chanock et al., 1994; Babior 1999; El Benna et al., 2005). The cytosolic proteins are p47phox (phox: pha- 
gocyte oxidase), p67phox, and p40phox, which interact with each other to form a complex and the small G-proteins, Rac1 (in monocytes) or Rac2 (in neutrophils) (Groemping et al., 2005). The membrane associated components of the NADPH oxidase are a glycosylated $91-\mathrm{kDa}$ protein (gp91phox or NOX2) and a 22-kDa subunit (p22phox) which together form the flavocytochrome $b_{558}$ (Vignais, 2002). The gp91phox/NOX2 subunit is the electron transfer chain of the active NADPH oxidase because it has binding sites for FAD, NADPH and two hemes. The spatial separation of the NADPH oxidase components ensures that the enzyme is dormant in resting cells. However, in response to stimulation, the cytosolic components migrate almost instantly to the membrane where they assemble with the flavocytochrome $b_{558}$ to form the active enzyme, a process that is tightly regulated by protein-protein interactions and by phosphorylation of p47phox (El Benna et al., 1994a; Faust et al., 1995; Quinn and Gauss, 2004; Groemping et al., 2005).

\section{Characteristic structural features of p47phox}

p47phox or NCF1 (for neutrophil cytosolic factor 1), is a protein composed of 390 amino acids with a molecular mass of $44.7 \mathrm{kDa}$ (Lomax et al., 1989; Volpp et al., 1989). It was estimated to be present in neutrophil cytosol at $100-150 \mathrm{ng} / 10^{6}$ cells (Leto et al., 1991; Jouan et al., 1993). The N-terminal amino acid sequence of p47phox has one PX (phox homology) domain (amino acids 4-121), the middle amino acid sequence of p47phox also contains two SH3 domains (amino acids 159-214 (SH3A) and amino acids 229-284 (SH3B)). Its $\mathrm{COOH}$-terminal sequence has a basic charge and is rich in serine and arginine residues and has at least one proline-rich region (PRR) (amino acids 363-368) (Groemping et al., 2005) (Figure 1).
In resting state the two p47phox-SH3 domains interact intramolecularly with the $\mathrm{C}$-terminal region of the non phosphorylated protein to keep p47phox in an auto-inhibited state (de Mendez et al., 1997; Greomping et al., 2003). For this reason the $\mathrm{C}$-terminal region is called the auto-inhibitory region (AIR). The X-ray structure of the auto-inhibited form of p47phox reveals that tandem $\mathrm{SH} 3$ domains share an interface which forms a shallow groove that constitutes the peptide binding surface (Groemping et al., 2003; Yuzawa et al., 2004a). In the auto-inhibited form, this site is occupied by the AIR polybasic region of p47phox and in the activated form it is occupied by a proline rich region of the cytoplasmic domain of p22phox (Yuzawa et al., 2004b).

\section{Phosphorylation of p47phox}

During human neutrophil stimulation, p47phox is heavily phosphorylated. This phosphoprotein was first identified since it was missing in neutrophils of some CGD-patients (Segal et al., 1985). In resting cells, p47phox is not phosphorylated with a highly basic charge $(\mathrm{pl}>9)$, as detected by NEPHGE (non-equilibrium $\mathrm{pH}$ gel electrophoresis) twodimensional gel analysis (Okamura et al., 1988). Upon phosphorylation, its $\mathrm{pl}$ shifts to acidic range, giving rise to several phosphorylated isoforms corresponding to different phosphorylated states. When cells are stimulated with PMA, the PKC activator, eight to nine phosphorylation states of p47phox are observed in the cytosol and membranes, with the two most acidic forms being located in the membrane (Rotrosen and Leto, 1990; El Benna et al., 1994b). This localized and stepwise phosphorylation in the cell indicate a sequential p47phox phosphorylation in the cytosol and membrane. Phosphorylation sites analysis revealed that $\mathrm{p} 47 \mathrm{phox}$ is phosphorylated in the carboxy-terminal portion of the protein obtained after cyanogen bromide $(\mathrm{CNBr})$ cleavage (El

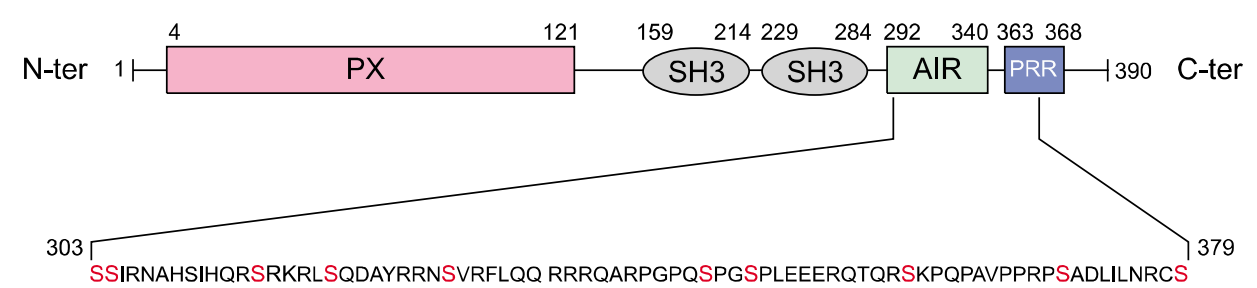

Figure 1. Domain structure of p47phox. p47phox is composed of 390 amino acids with one phox homology (PX) domain (amino acids 4-121), two src homology 3 domains (SH3) domains (amino acids 159-214 (SH3A) and amino acids 229-284 (SH3B)), one autoinhibitory region (AIR) (amino acids 292-340) and a proline-rich region (PRR) (amino acids 363-368). The C-terminal region contains several phosphorylated serines (in red). 
Benna et al., 1994a). This C-terminal fragment contains multiple phosphorylated sites encompassing serines 303 to 379 (El Benna et al., 1994a; 1996b).

Regarding the role of the p47phox phosphorylated sites in NADPH oxidase activation, results obtained from combined mutation of all phosphorylated serines (Ser303, Ser304, Ser315, Ser320, Ser328, Ser345, Ser348, Ser359, Ser370 and Ser379) demonstrated that p47phox phosphorylation is absolutely required for NADPH oxidase activation in EBV-transformed lymphocytes B (Faust et al., 1995). Individual mutation of each serine showed that only the mutation of serine 379 to alanine completely inhibited NADPH oxidase activation (Faust et al., 1995), while mutation of serine 303 alone or 304 or 328 or 359 or 370 to alanine inhibited almost $50 \%$ NADPH oxidase activation, and mutation of serine 315 or 320 or 348 to alanine had no effect. Double mutations revealed that two pairs of phosphorylated serines (serines $(303+304)$ and serines $(359+370)$ ) are necessary for NADPH oxidase activation (Inanami et al., 1998; Johnson et al., 1998). The importance of these phosphorylated sites of p47phox was also shown in COS-phox cells stimulated with PMA (Price et al., 2002) or a physiological stimulus such as fMLF (Cheng et al., 2007).

In in vitro conditions, p47phox is phosphorylated on selective sites by different type of protein kinases such as PKC $\alpha, \beta, \delta$, and $\zeta$ (Dang et al., 2001a; Fontayne et al., 2002), PKA (El Benna et al., 1996a; Kramer et al., 1988), MAPKinase ERK2 and p38MAPKinase (El Benna et al., 1996b), protein casein kinase 2 (CKII) (Park et al., 2001), AKT (Chen et al., 2003; Hoyal et al., 2003), IRAK-4 (Pacquelet et al., 2007), p21- activated kinase (PAK) (Martyn et al., 2005), a phosphatidic acid-activated kinase (Waite et al., 1997) and src kinase (Chowdhury et al., 2005).

In agreement with the above selective phosphorylation of $\mathrm{p} 47$ phox, it seems that in vivo, depending on the nature of the agonist encountered by neutrophils, a combination of kinases could participate to the phosphorylation of p47phox. Various protein kinases have been implicated in the phosphorylation of $\mathrm{p} 47 \mathrm{phox}$ and regulation of NADPH oxidase in intact cells. Thus PKC $\zeta$ (Dang et al., 2001a), PKC $\beta$ (Dekker et al., 2000; Korchak et al., 2001), PKC $\delta$ (Bey et al., 2004; Brown et al., 2003; Cheng et al., 2007), PAK (Martyn et al., 2005), ERK1/2 (Dewas et al., 2000) and AKT (Chen et al., 2003) were shown to play a stimulatory role in $\mathrm{AMLF}$ - or PMA-induced NADPH oxidase activation. Proinflammatory cytokines such as GM-CSF and TNF $\alpha$ which do not activate
NADPH oxidase but prime its activation in response to a secondary stimulus such as fMLF (El Benna et al., 2008), induce partial phosphorylation of p47phox on Ser345 by ERK1/2 or p38MAPK and promote NADPH oxidase assembly (Dang et al., 1999, 2006; Dewas et al., 2003). While phosphorylation of p47phox by PKC, PAK and AKT in neutrophils has a positive stimulatory effect on NADPH oxidase activation and pre-phosphorylation by p38MAPkinase and ERK1/2 results in the enhancement of this effect, some data have suggested that the phosphorylation of p47phox by PKA or CKII could have a negative inhibitory effect (Bengis-Garber et al., 1996; Park et al., 2001).

\section{p47phox the phagocyte NADPH oxydase (NOX2) organizer (NOXO2) undergoes conformational changes upon cell activation}

NADPH oxidase is dormant in resting cells but becomes active when cells are stimulated. In resting cells, almost $100 \%$ of p47phox is located in the cytosol alone or in a complex containing equimolar of p67phox and p40phox (Park et al., 1994; Lapouge et al., 2002). As described above, in resting non phosphorylated state, the two p47phox-SH3 domains, interact intramolecularly with the p47phox C-terminal sequence to keep the protein in an auto-inhibitory state. p47phox also interacts with p67phox and p40phox via their respective $\mathrm{SH} 3$ domains and $\mathrm{PRR}$ sequences (Wientjes et al., 1996; Grizot et al., 2001) or non PRR sequences (Kami et al., 2002).

During activation, approximately $10-20 \%$ of these proteins migrate to the plasma membrane (Clark et al., 1990; El Benna et al., 1994b) and the 80-90\% of $\mathrm{p} 47$ phox remain in the cytosol. p47phox binds to cytochrome $b_{558}$ (gp91phox/NOX2 and p22phox) during activation since translocation of p47phox to the plasma membranes is impaired in neutrophils from gp91phox or p22phox deficient CGD patients (Heyworth et al., 1991). While cytochrome $b_{558}$ is the central docking site for the cytosolic components that translocate to the plasma membrane, p47phox is the subunit responsible for transporting the whole cytosolic complex (p47phox-p67phoxp40phox) to the docking site during NADPH oxidase activation. It mediates the early binding step to gp91phox/NOX2 and to p22phox and subsequently allows p67phox to interact with and to activate gp91phox/NOX2 (De Leo et al., 1996; Dang et al., 2001b; Nisimoto et al., 1999). It is considered as the organizer subunit since it coordinates 
the interaction of the different NADPH oxidase subunits allowing the formation of an active complex.

When $\mathrm{p} 47$ phox is phosphorylated, the interaction of the SH3 domains switches from the AIR to the p22phox-polyproline rich-sequence (Ago et al., 1999; Huang et al., 1999; Greomping et al., 2003). It implies that phosphorylation induces conformational changes of p47phox. Several reports suggest that p47phox phosphorylation induces conformational changes of the protein (Park and Babior, 1997; Swain et al., 1997; Park and Park, 1998). In resting state, p47phox has a constrained conformation due to the tight interaction between $\mathrm{SH} 3$ domains and the AIR (Yuzawa et al., 2004a). Phosphorylation of p47phox in its carboxy-terminal tail relaxes this interaction, allowing the binding of the cryptic $\mathrm{SH} 3$ domains to the proline-rich region of p22phox (Figure 2). Phosphorylation of only three sites of p47phox (Ser303, 304 and 328) is required to induce this conformational change to a state accessible for p22phox thereby bringing p67phox and p40phox in proximity to gp91phox/NOX2 initiating assembly of the enzyme (Shiose and Sumimoto, 2000).

p47phox has a PX domain (a sequence of about 125 amino acids) which binds to phosphatidylinositol 3,4-biphosphate and phosphatidic acid (Kanai et al., 2001; Karathanassis et al., 2002; Stahelin et al., 2003). Upon phosphorylation of the C-terminal region of $\mathrm{p} 47$ phox, the $\mathrm{PX}$ domain is also released which allows its binding to phosphatidylinositol 3,4-biphosphate and phosphatidic acid (Karathanassis et al., 2002; Ago et al., 2003). This binding is important for membrane localization of the complex and may help to assemble the NADPH oxidase complex at precise sites of the ingested pathogens (Zhan et al., 2002; Stahelin et al., 2003). During activation p47phox also binds to the cytoskeleton and membrane cytoskeleton (Nauseef et al., 1991; Woodman et al, 1991; El Benna et al., 1994b, 1999). The p47phox PX domain binds also to moesin (Wientjes et al., 2001) and this PX/moesin-interaction could mediate association of $\mathrm{p} 47 \mathrm{phox}$ to actin cytoskeleton (Zhan et al., 2004).

\section{Implication of p47phox in diseases}

\section{Chronic Granulomatous Disease (CGD)}

The importance of p47phox and ROS production by NADPH oxidase in host defenses is illustrated by a life-threatening genetic disorder called chronic granulomatous disease (CGD), in which the NADPH oxidase enzyme is dysfunctional in phagocytes, leading to life-threatening bacterial and fungal infections (Dinauer, 1993; Roos et al., 1996). CGD is an inherited immune deficiency in which human phagocytes are unable to produce ROS. Recurrent, often life-threatening bacterial and fungal infections usually start during childhood. Common infectious syndromes include pneumonia and lung abscesses, skin and soft tissue infections, lymphadenopathy, suppurative lymphadenitis, osteomyelitis and hepatic abscesses. The most common pathogens encountered in CGD patients are gram-positive bacteria (Staphylococcus aureus), gram-negative bacteria (Salmonella, Pseudomonas cepacia, Serratia marcescens...) and fungi (Aspergillus, Candida albicans). Aspergillus species can cause intractable pneumonia and sometimes septicemia in CGD patients, and are a frequent cause of death (Meischl and Roos, 1998; Kannengiesser et al., 2008). CGD results from mutations in the NADPH oxidase component genes, namely the CYBB gene (Xp21)

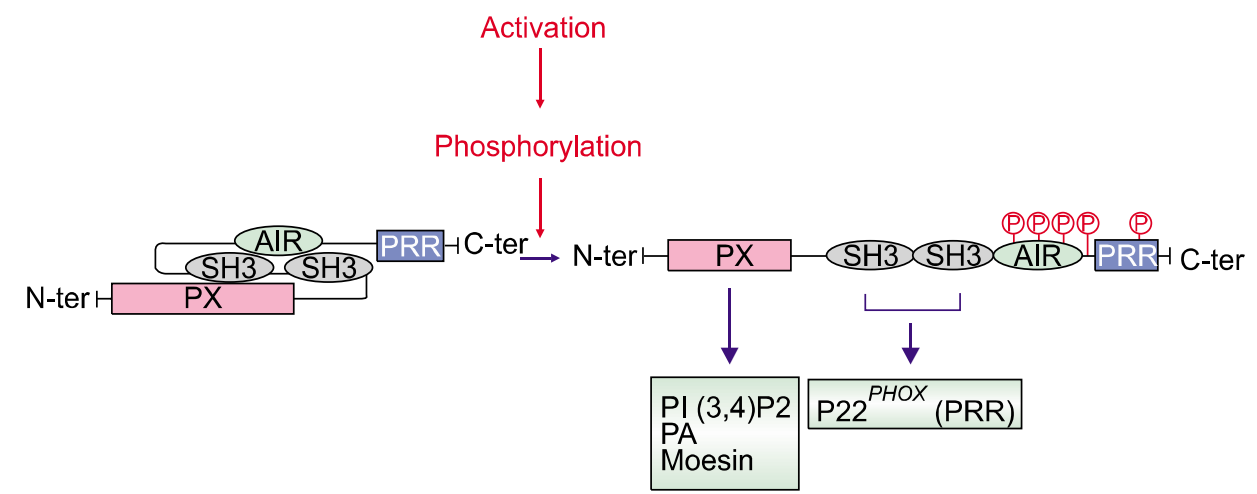

Figure 2. Phosphorylation of p47phox induces conformational changes and changes domains interactions. In resting state the two p47phox-SH3 domains interact with the C-terminal region AIR to keep the protein in an auto-inhibited state. Upon activation, p47phox is phosphorylated, this phosphorylation induces conformational changes allowing the binding of the cryptic SH3 domains to the proline-rich region (PRR) of p22phox and PX domain to phosphatidylinositol 3,4-biphosphate (PI3,4P), phosphatidic acid (PA) and moesin. 
that encodes the gp91phox subunit, and the CYBA gene (16q24), the NCF1 gene $(7 q 11)$ and the NCF2 gene (1q25) which encode p22phox, p47phox, p67phox, respectively. The most frequent form of CGD (approximately $70 \%$ of all cases) is the X-linked gp91phox-deficient form, followed by the autosomal form deficient in p47phox (approximately 25\%) (Meischl and Roos, 1998; Kannengiesser et al., 2008). Less frequent forms are autosomal CGD deficient in p67phox $(<5 \%)$ and p22phox ( $<5 \%$ ) (Roos et al., 1996). Most of the p47phox deficient patients have a GT deletion at the start of exon two, resulting in a frameshift and lack of expression of the protein (Gorlach et al., 1997).

The importance of $p 47 p h o x$ in host defense was also demonstrated in a p47phox knockout mice (Jackson et al., 1995). These mice developed lethal infections and granulomatous inflammation similar to those encountered in human CGD patients. This animal model mirrors human CGD and confirms a critical role for the phagocyte NADPH oxidase in mammalian host defense.

\section{Atherosclerosis}

ROS are important contributors to the pathophysiology of human vascular diseases such as atherosclerosis and hypertension. The expression of NADPH oxidase subunits in human coronary arteries is correlated with the severity of atherosclerosis (Lavigne et al, 2001; Clempus and Griendling, 2006). NADPH oxidase and its subunit p47phox are indeed expressed in human and mice smooth muscle cells which produce ROS (Lavigne et al, 2001). It was hypothesized that NADPH oxidase is involved in growth factor-induced smooth muscle cell proliferation and atherosclerosis (Brandes et al., 2002). Chen et al. (2004) have observed decreased neointimal formation in gp91phox/NOX2deficient mice in response to arterial injury. Since p47phox regulates the activation of NOX2, excessive NOX2 activation via p47phox dysregulation could be involved in this process. Barry-Lane et al. (2001) showed that p47phox is required for atherosclerosis lesion progression in $\mathrm{ApoE}^{-/-}$mice. Indeed, atherogenic mice deficient in p47phox $\left(\mathrm{ApoE}^{-/ /} / \mathrm{p} 47 \mathrm{phox}^{-/}\right)$had less lesion area than atherogenic mice $\left(\mathrm{ApoE}^{-/-}\right)$.

\section{Rheumatoid Arthritis}

Although ROS production by NADPH oxidase plays a key role in host defenses against microbial pathogens, excessive ROS release can also damage bystander host tissues, thereby amplifying inflammatory reactions (Babior 1984, 2000; El Benna et al., 2008). Increasing evidence suggests that NADPH oxidase is involved in inflammatory diseases such as rheumatoid arthritis. Rheumatoid arthritis (RA) is a systemic inflammatory disorder most commonly targeting the joints. The pathophysiology of RA involves dysregulated cytokine production and neutrophil accumulation in synovial fluid (Firestein, 2004). Synovial fluid from arthritic patients contains a large number of neutrophils and macrophages suggesting that they may contribute to tissue injury. NADPH oxidase activity and phosphorylation of p47phox is highly increased in neutrophils from arthritic patients (Dang et al., 2006). This up-regulation could be due to the action of proinflammatory cytokines such as TNF $\alpha$, which is found in high concentrations in the synovial fluids of these patients. Using p47phox ${ }^{-/-}$ mice, Van Lent et al. (2005) showed that NADPHoxidase-driven ROS production determines chondrocytes death. These cells are important cells in the joints death and partly regulates metalloprotease- mediated cartilage matrix degradation during interferon gamma stimulated immune complex arthritis.

\section{Hepatic fibrosis}

Liver fibrosis is the common consequence of chronic liver injury (Albanis and Friedman, 2001). ROS produced by different cells in the liver play an important role in this process (Parola and Robino, 2001). Human hepatic stellate cells (HSCs), a fibrogenic cell type, express $\mathrm{p} 47 \mathrm{phox}$ and produce ROS. Angiotensin II a pro-oxidant and fibrogenic cytokine, which induces phosphorylation of p47phox and ROS production. In a experimental liver fibrosis model, p47phox ${ }^{-/-}$mice showed attenuated liver injury and fibrosis compared to wild type mice (Bataller et al., 2003).

\section{Conclusion}

The phagocyte NADPH oxidase plays a key role in host defense against microbial pathogens by generating superoxide anion and other ROS molecules. Excessive ROS release can also damage surrounding host tissues involved in inflammatory reaction. A tight regulation of the NADPH oxidase complex is therefore necessary to avoid tissue injuries. p47phox with its different domains and several phosphorylated sites is a main regulator of NADPH oxidase activation by organizing the complex. Thus p47phox is the phagocyte NADPH oxidase (NOX2) organizer. 
Better understanding of the different mechanisms and transduction pathways involved in p47phox phosphorylation and interaction will be necessary to design new therapeutic agents to downregulate ROS hyperproduction in inflammatory diseases without decreasing the normal response to bacterial-derived stimuli.

\section{Acknowledgments}

This work was supported by grants from Association de la Recherche sur la Polyarthrite (ARP), Association pour la recherche sur le cancer (ARC), Institut National de Santé et de la Recherche Médicale (INSERM), Université Paris 7 and le Centre National de la Recherche Scientifique (CNRS).

\section{References}

Ago T, Nunoi $H$, Ito T, Sumimoto $H$. Mechanism for phosphorylation-induced activation of the phagocyte NADPH oxidase protein $\mathrm{p} 47$ (phox). Triple replacement of serines 303,304 , and 328 with aspartates disrupts the $\mathrm{SH} 3$ domain-mediated intramolecular interaction in p47(phox), thereby activating the oxidase. J Biol Chem 1999;274: 33644-53

Ago T, Kuribayashi F, Hiroaki H, Takeya R, Ito T, Kohda D, Sumimoto $\mathrm{H}$. Phosphorylation of p47phox directs phox homology domain from $\mathrm{SH} 3$ domain toward phosphoinositides, leading to phagocyte NADPH oxidase activation. Proc Natl Acad Sci USA 2003;100:4474-9

Albanis E, Friedman SL. Hepatic fibrosis. Pathogenesis and principles of therapy. Clin Liver Dis 2001;5:315-34

Babior BM. Oxidants from phagocytes: agents of defense and destruction. Blood 1984;64: 959-66

Babior BM. NADPH Oxidase: an update. Blood 1999;93: 1464-76

Babior BM. Phagocytes and oxidative stress. Am J Med 2000;109:33-44

Barry-Lane PA, Patterson C, van der Merwe M, Hu Z, Holland SM, Yeh ET, Runge MS. p47phox is required for atherosclerotic lesion progression in $\mathrm{ApoE}(-/-)$ mice. J Clin Invest 2001;108:1513-22

Bataller R, Schwabe RF, Choi YH, Yang L, Paik YH, Lindquist $\mathrm{J}$, Qian T, Schoonhoven R, Hagedorn CH, Lemasters JJ, Brenner DA. NADPH oxidase signal transduces angiotensin II in hepatic stellate cells and is critical in hepatic fibrosis. J Clin Invest 2003;112:1383-94

Bengis-Garber C, Gruener N. Protein kinase A downregulates the phosphorylation of $\mathrm{p} 47$ phox in human neutrophils: a possible pathway for inhibition of the respiratory burst. Cell Signal 1996;8:291-6

Bey EA, Xu B, Bhattacharjee A, Oldfield CM, Zhao X, Li Q, Subbulakshmi V, Feldman GM, Wientjes FB, Cathcart MK. Protein kinase $C$ delta is required for p47phox phosphorylation and translocation in activated human monocytes.

\section{J Immunol 2004;173:5730-8}

Brandes RP, Miller FJ, Beer S, Haendeler J, Hoffmann J, Ha T, Holland SM, Gorlach A, Busse R. The vascular NADPH oxidase subunit $\mathrm{p} 47 \mathrm{phox}$ is involved in redox-mediated gene expression. Free Radic Biol Med 2002;32:1116-22

Brown GE, Stewart MQ, Liu H, Ha VL, Yaffe MB. A novel assay system implicates Ptdlns(3,4)P(2), Ptdlns(3)P, and PKC delta in intracellular production of reactive oxygen species by the NADPH oxidase. Mol Cell 2003;11:35-47

Chanock SJ, El-Benna J, Smith RM and Babior BM. The respiratory burst oxidase. J Biol Chem 1994;269:24519-22

Chen Q, Powell DW, Rane MJ, Singh S, Butt W, Klein JB, McLeish KR. Akt phosphorylates p47phox and mediates respiratory burst activity in human neutrophils. J Immunol 2003; $170: 5302-8$

Chen Z, Keaney JF Jr, Schulz E, Levison B, Shan L, Sakuma $M$, Zhang X, Shi C, Hazen SL, Simon DI. Decreased neointimal formation in Nox2-deficient mice reveals a direct role for NADPH oxidase in the response to arterial injury. Proc Natl Acad Sci USA 2004;101:13014-9

Cheng N, He R, Tian J, Dinauer MC, Ye RD. A critical role of protein kinase $C$ delta activation loop phosphorylation in formyl-methionyl-leucyl-phenylalanine-induced phosphorylation of $\mathrm{p} 47$ (phox) and rapid activation of nicotinamide adenine dinucleotide phosphate oxidase. J Immunol 2007;179:7720-8

Chowdhury AK, Watkins T, Parinandi NL, Saatian B, Kleinberg ME, Usatyuk PV, Natarajan V. Src-mediated tyrosine phosphorylation of p47phox in hyperoxia-induced activation of NADPH oxidase and generation of reactive oxygen species in lung endothelial cells. J Biol Chem 2005;280:20700-11

Clark RA, Volpp BD, Leidal KG, Nauseef WM. Two cytosolic components of the human neutrophil respiratory burst oxidase translocate to the plasma membrane during cell activation. J Clin Invest 1990;85:714-21

Clempus RE, Griendling KK. Reactive oxygen species signaling in vascular smooth muscle cells. Cardiovasc Res 2006;71: 216-25

Dang PM, Dewas C, Fay M, Gougerot-Pocidalo MA and El Benna J. Priming of human neutrophil respiratory burst by granulocyte/macrophage colony-stimulating factor (GMCSF) involves partial phosphorylation of p47phox. J Biol Chem 1999;274:20704-8

Dang PM, Fontayne A, Hakim J, El Benna J, and Périanin A. Protein kinase C z (zeta) phosphorylates a subset of selective sites of the NADPH oxidase component p47phox and regulates the respiratory burst of f-Met-Leu-Phestimulated human neutrophils. J Immunol 2001a;166: 1206-13

Dang PM, Cross AR and Babior BM. Assembly of the neutrophil respiratory burst oxidase: $A$ direct interaction between p67phox and cytochrome b558. Proc Nat Acad Scien 2001b;98:3001-5

Dang PM, Stensballe A, Boussetta T, Raad H, Dewas C, Kroviarski Y, Hayem G, Jensen ON, Gougerot-Pocidalo MA, 
El-Benna J. A specific p47phox -serine phosphorylated by convergent MAPKs mediates neutrophil NADPH oxidase priming at inflammatory sites. J Clin Invest 2006;116: 2033-43

Dekker LV, Leitges M, Altschuler G, Mistry N, McDermott A, Roes J, Segal AW. Protein kinase C-beta contributes to NADPH oxidase activation in neutrophils. Biochem $\mathrm{J}$ 2000;347 Pt 1:285-9

De Leo FR, Ulman KV, Davis AR, Jutila KL, Quinn MT. Assembly of the human neutrophil NADPH oxidase involves binding of p67phox and flavocytochrome $b$ to a common functional domain in p47phox. J Biol Chem 1996; 271: 17013-20

de Mendez I, Homayounpour N, Leto TL. Specificity of p47phox $\mathrm{SH} 3$ domain interactions in NADPH oxidase assembly and activation. Mol Cell Biol 1997;17:2177-85

Dewas C, Gougerot-Pocidalo MA, and El Benna J. The Mitogen - Activated Protein Kinase Extracellular SignalRegulated Kinase $1 / 2$ Pathway is involved in formylMethionyl-Leucyl-Phenylalanine-Induced p47phox phosphorylation in human neutrophils. J Immunol 2000;165: 5238-44

Dewas C, Dang PM, Gougerot-Pocidalo M-A, and El Benna J. TNF induces phosphorylation of p47phox in human neutrophils: partial phosphorylation of $p 47$ phox is a common event of priming of human neutrophils by TNF and granulocyte-macrophage colony-stimulating factor. J Immunol 2003;171:4392-8

Dinauer MC. The respiratory burst oxidase and the molecular genetics of chronic granulomatous disease. Crit Rev Clin Lab Sci 1993;30:329-69

El Benna J, Faust LP, Babior BM. The phosphorylation of the respiratory burst oxidase component p47phox during neutrophil activation. Phosphorylation of sites recognized by protein kinase $\mathrm{C}$ and by proline-directed kinases. J Biol Chem 1994a;269:23431-6

El Benna J, Ruedi JM, Babior BM. Cytosolic guanine nucleotide-binding protein Rac 2 operates in vivo as a component of the neutrophil respiratory burst oxidase. Transfer of Rac 2 and the cytosolic oxidase components p47 (phox) and p67 (phox) to the submembranous actin cytoskeleton during oxidase activation. J Biol Chem 1994b; 269:6729-34

El Benna J, Faust LRP, Johnson J, Babior BM. Phosphorylation of the respiratory burst oxidase subunit p47phox as determined by two-dimensional phosphopeptide mapping. Phosphorylation by protein kinase $C$, protein kinase $A$ and a mitogen activated protein kinase. J Biol Chem 1996a;271:6374-8

El Benna J, Han J, Park JW, Schmid E, Ulevitch RJ, Babior BM. Activation of p38 in stimulated human neutrophils: phosphorylation of the oxidase component p47phox by p38 and ERK but not by JNK. Arch Biochem Biophys 1996b; 334:395-400

El Benna J, Dang PM, Andrieu V, Vergnaud S, Dewas C, Cachia O, Fay M, Morel F, Chollet-Martin S, Hakim J, Gougerot-Pocidalo MA. P40phox associates with the neutrophil Triton $\mathrm{X}$-100-insoluble cytoskeletal fraction and PMA-activated membrane skeleton: a comparative study with P67phox and p47phox. J Leukoc Biol 1999;66:1014-20

El-Benna J, Dang PM, Gougerot-Pocidalo MA, Elbim C. Phagocyte NADPH oxidase: a multicomponent enzyme essential for host defenses. Arch Immunol Ther Exp (Warsz) 2005; 53:199-206

El-Benna J, Dang PM, Gougerot-Pocidalo MA. Priming of the neutrophil NADPH oxidase activation: role of p47phox phosphorylation and NOX2 mobilization to the plasma membrane. Semin Immunopathol 2008;30:279-89

Faust LP, El Benna J, Babior BM, Chanock SJ. The phosphorylation targets of p47 phox a subunit of the respiratory burst oxidase. Functions of the individual target serines as evaluated by site-directed mutagenesis. J Clin Invest 1995;96:1499-505

Firestein GS. The T cell cometh: interplay between adaptive immunity and cytokine networks in rheumatoid arthritis. J Clin Invest 2004;114:471-4

Fontayne A, Dang PM, Gougerot-Pocidalo MA, El-Benna J. Phosphorylation of p47phox sites by PKC alpha, beta II, delta, and zeta: effect on binding to p22phox and on NADPH oxidase activation. Biochemistry 2002;41:7743-50

Görlach A, Lee PL, Roesler J, Hopkins PJ, Christensen B, Green ED, Chanock SJ, Curnutte JT. A p47-phox pseudogene carries the most common mutation causing p47-phox- deficient chronic granulomatous disease. J Clin Invest 1997;100:1907-18

Grizot S, Grandvaux N, Fieschi F, Fauré J, Massenet C, Andrieu JP, Fuchs A, Vignais PV, Timmins PA, Dagher MC, Pebay-Peyroula E. Small angle neutron scattering and gel filtration analyses of neutrophil NADPH oxidase cytosolic factors highlight the role of the C-terminal end of p47phox in the association with p40phox. Biochemistry 2001;40:312733

Groemping Y, Lapouge K, Smerdon SJ, Rittinger K. Molecular basis of phosphorylation-induced activation of the NADPH oxidase. Cell 2003;113:343-55

Groemping Y, Rittinger K. Activation and assembly of the NADPH oxidase: a structural perspective. Biochem J 2005; 386:401-16

Hampton MB, Kettle AJ, Winterbourn CC. Inside the neutrophil phagosome: oxidants, myeloperoxidase, and bacterial killing. Blood 1998;92:3007-17

Heyworth PG, Curnutte JT, Nauseef WM, Volpp BD, Pearson $D W$, Rosen H, Clark RA. Neutrophil nicotinamide adenine dinucleotide phosphate oxidase assembly. Translocation of p47-phox and p67-phox requires interaction between p47-phox and cytochrome b558. J Clin Invest 1991;87:352-6

Hoyal CR, Gutierrez A, Young BM, Catz SD, Lin JH, Tsichlis $\mathrm{PN}$, Babior BM. Modulation of p47PHOX activity by site-specific phosphorylation: Akt-dependent activation of the NADPH oxidase. Proc Natl Acad Sci USA 2003;100: 5130-5

Huang J, Kleinberg ME. Activation of the phagocyte NADPH oxidase protein p47(phox). Phosphorylation controls $\mathrm{SH} 3$ 
domain-dependent binding to p22(phox). J Biol Chem 1999; 274:19731-7

Inanami O, Johnson JL, McAdara JK, EI Benna J, Faust LR, Newburger PE, Babior BM. Activation of the leukocyte NADPH oxidase by phorbol ester requires p47phox phosphorylation on serine 303 or 304. J Biol Chem 1998; 273:9539-43

Jackson SH, Gallin JI, Holland SM. The p47phox mouse knock-out model of chronic granulomatous disease. J Exp Med 1995;182:751-8

Johnson JL, Park JW, EI Benna J, Faust LR, Inanami O, and Babior BM. Activation of p47phox, a cytosolic subunit of the leukocyte NADPH oxidase. Phosphorylation of ser359 or 370 precedes phosphorylation at other sites and is required for activity. J Biol Chem 1998;273:35147-52

Jouan A, Pilloud-Dagher MC, Fuchs A, Vignais PV. A generally applicable ELISA for the detection and quantitation of the cytosolic factors of NADPH-oxidase activation in neutrophils. Anal Biochem 1993;214:252-9

Kami K, Takeya R, Sumimoto H, Kohda D. Diverse recognition of non-PxxP peptide ligands by the $\mathrm{SH} 3$ domains from p67(phox), Grb2 and Pex13p. EMBO J 2002;21: 4268-76

Kanai F, Liu H, Field SJ, Akbary H, Matsuo T, Brown GE, Cantley LC, Yaffe MB. The PX domains of p47phox and p40phox bind to lipid products of $\mathrm{PI}(3) \mathrm{K}$. Nat Cell Biol 2001;3:675-8

Kannengiesser C, Gérard B, El Benna J, Henri D, Kroviarski Y, Chollet-Martin S, Gougerot-Pocidalo MA, Elbim C, Grandchamp B. Molecular epidemiology of chronic granulomatous disease in a series of 80 kindreds: identification of 31 novel mutations. Hum Mutat 2008;29:E132-E49

Karathanassis D, Stahelin RV, Bravo J, Perisic O, Pacold CM, Cho W, Williams RL. Binding of the PX domain of p47(phox) to phosphatidylinositol 3,4-bisphosphate and phosphatidic acid is masked by an intramolecular interaction. EMBO J 2002;21:5057-68

Korchak HM, Kilpatrick LE. Roles for beta II-protein kinase $\mathrm{C}$ and RACK1 in positive and negative signaling for superoxide anion generation in differentiated HL60 cells. J Biol Chem 2001;276:8910-7

Kramer IM, van der Bend RL, Verhoeven AJ, Roos D. The 47-kDa protein involved in the NADPH:O2 oxidoreductase activity of human neutrophils is phosphorylated by cyclic AMP-dependent protein kinase without induction of a respiratory burst. Biochim Biophys Acta 1988;971:189-96

Lapouge K, Smith SJ, Groemping Y, Rittinger K. Architecture of the p40-p47-p67phox complex in the resting state of the NADPH oxidase. A central role for p67phox. J Biol Chem 2002;277:10121-8

Lavigne MC, Malech HL, Holland SM, Leto TL. Genetic demonstration of p47phox-dependent superoxide anion production in murine vascular smooth muscle cells. Circulation 2001;104:79-84

Leto TL, Garrett MC, Fujii $\mathrm{H}$, Nunoi $\mathrm{H}$. Characterization of neutrophil NADPH oxidase factors p47-phox and p67-phox from recombinant baculoviruses. J Biol Chem 1991;266: 19812-8

Lomax KJ, Leto TL, Nunoi H, Gallin JI, Malech HL. Recombinant 47-kilodalton cytosol factor restores NADPH oxidase in chronic granulomatous disease. Science 1989;245:409-12. Erratum in: Science 1989;246:987

Martyn KD, Kim MJ, Quinn MT, Dinauer MC, Knaus UG. p21-activated kinase (Pak) regulates NADPH oxidase activation in human neutrophils. Blood 2005;106:3962-69

Meischl C, Roos D. The molecular basis of chronic granulomatous disease. Springer Semin Immunopathol 1998;19:417-34

Nathan C. Neutrophils and immunity: challenges and opportunities. Nat Rev Immunol 2006;6:173-82

Nauseef WM, Volpp BD, McCormick S, Leidal KG, Clark RA. Assembly of the neutrophil respiratory burst oxidase. Protein kinase $\mathrm{C}$ promotes cytoskeletal and membrane association of cytosolic oxidase components. J Biol Chem 1991;266: 5911-7

Nisimoto Y, Motalebi S, Han CH, Lambeth JD. (1999) The p67(phox) activation domain regulates electron flow from NADPH to flavin in flavocytochrome $\mathrm{b}(558)$. J Biol Chem 1999;274: 22999-3005

Okamura N, Curnutte JT, Roberts RL, and Babior BM. Relationship of protein phosphorylation to the activation of the respiratory burst in human neutrophils. Defect in the phosphorylation of a group of closely related $48-\mathrm{kDa}$ proteins in two forms of chronic granulomatous disease. J Biol Chem 1988;263: 6777-82

Pacquelet S, Johnson JL, Ellis BA, Brzezinska AA, Lane WS, Munafo DB, Catz SD. Cross-talk between IRAK-4 and the NADPH oxidase. Biochem J 2007;403:451-61

Park H-S, Park J-W. Conformational changes of leukocyte NADPH oxidase subunit p47phox during activation studied through its intrinsic fluorescence. Biochim Biophys Acta 1998;1387:406-11

Park HS, Lee SM, Lee JH, Kim YS, Bae YS, Park JW. Phosphorylation of the leucocyte NADPH oxidase subunit p47(phox) by casein kinase 2: conformation-dependent phosphorylation and modulation of oxidase activity. Biochem J 2001;358(Pt 3):783-90

Park JW, Benna JE, Scott KE, Christensen BL, Chanock SJ, Babior BM. Isolation of a complex of respiratory burst oxidase components from resting neutrophil cytosol. Biochemistry 1994;33:2907-11

Park JW, Babior BM. Activation of the leukocyte NADPH oxidase subunit p47phox by protein kinase C. A phosphorylation-dependent change in the conformation of the C-terminal end of p47phox. Biochemistry 1997;36 7474-80

Parola M, Robino G. Oxidative stress-related molecules and liver fibrosis. J Hepatol 2001; 35: 297-306

Price MO, McPhail LC, Lambeth JD, Han CH, Knaus UG, Dinauer MC. Creation of a genetic system for analysis of the phagocyte respiratory burst: high-level reconstitution of the NADPH oxidase in a nonhematopoietic system. Blood 2002;99:2653-61 
Quinn MT, Gauss KA. Structure and regulation of the neutrophil respiratory burst oxidase: comparison with nonphagocyte oxidases. J Leukoc Biol 2004;76:760-81

Roos D, De Boer M, Kuribayashi F, Meischl, Weening RS, Segal AW, Ahlin A, Nemet K, Hossle JP, BernatowskaMatusskiewicz and middleton-Price $\mathrm{H}$ : Mutations in the $X$-Linked and Autosomal recessive forms of chronic granulomatous disease. Blood 1996,87:1663-81

Rotrosen D, Leto TL. Phosphorylation of neutrophil 47-kDa cytosolic oxidase factor. Translocation to membrane is associated with distinct phosphorylation events. J Biol Chem 1990; 265:19910-5

Segal AW, Heyworth PG, Cockcroft S, Barrowman M. Stimulated neutrophils from patients with autosomal recessive chronic granulomatous disease fail to phosphorylate a Mr-44 000 protein. Nature 1985;316:547-9

Segal AW. How neutrophils kill microbes. Annu Rev Immunol 2005;23:197-223

Shiose A, Sumimoto H. Arachidonic acid and phosphorylation synergistically induce a conformational change of p47phox to activate the phagocyte NADPH oxidase. J Biol Chem 2000;275:13793-801

Stahelin RV, Burian A, Bruzik KS, Murray D, Cho W. Membrane binding mechanisms of the PX domains of NADPH oxidase p40phox and p47phox. J Biol Chem 2003;278:14469-79

Swain SD, Helgerson SL, Davis AR, Nelson L K, and Quinn MT. Analysis of activation-induced conformational changes in p47phox using tryptophan fluorescence spectroscopy. J Biol Chem 1997;272:29502-9

van Lent PL, Nabbe KC, Blom AB, Sloetjes A, Holthuysen AE, Kolls J, Van De Loo FA, Holland SM, Van Den Berg WB. NADPH-oxidase-driven oxygen radical production determines chondrocyte death and partly regulates metalloproteinase-mediated cartilage matrix degradation during interferon-gamma-stimulated immune complex arthritis. Arthritis Res Ther 2005;7:R885-95

Vignais PV. The superoxide-generating NADPH oxidase: structural aspects and activation mechanism. Cell Mol Life Sci 2002;59:1428-59

Volpp BD, Nauseef WM, Donelson JE, Moser DR, Clark RA.
Cloning of the cDNA and functional expression of the 47-kilodalton cytosolic component of human neutrophil respiratory burst oxidase. Proc Natl Acad Sci USA 1989; 86:7195-9. Erratum in: Proc Natl Acad Sci USA 1989; $86: 9563$

Waite KA, Wallin R, Qualliotine-Mann D, McPhail LC. Phosphatidic acid-mediated phosphorylation of the NADPH oxidase component p47-phox. Evidence that phosphatidic acid may activate a novel protein kinase. J Biol Chem 1997;272:15569-78

Wientjes FB, Panayotou G, Reeves E, Segal AW. Interactions between cytosolic components of the NADPH oxidase: p40phox interacts with both p67phox and p47phox. Biochem J 1996;317( Pt 3):919-24

Wientjes FB, Reeves EP, Soskic V, Furthmayr H, Segal AW. The NADPH oxidase components p47(phox) and p40(phox) bind to moesin through their PX domain. Biochem Biophys Res Commun 2001;289:382-8

Woodman RC, Ruedi JM, Jesaitis AJ, Okamura N, Quinn MT, Smith RM, Curnutte JT, Babior BM. Respiratory burst oxidase and three of four oxidase-related polypeptides are associated with the cytoskeleton of human neutrophils. J Clin Invest 1991;87:1345-51

Yuzawa S, Ogura K, Horiuchi M, Suzuki NN, Fujioka Y, Kataoka M, Sumimoto $H$, Inagaki F. Solution structure of the tandem Src homology 3 domains of p47phox in an autoinhibited form. J Biol Chem 2004b;279: 29752-60

Yuzawa S, Suzuki NN, Fujioka Y, Ogura K, Sumimoto H, Inagaki F. A molecular mechanism for autoinhibition of the tandem SH3 domains of p47phox,the regulatory subunit of the phagocyte NADPH oxidase. Genes Cells 2004a;9: 443-56. Erratum in: Genes Cells 2004,9:609

Zhan Y, He D, Newburger PE, Zhou GW. p47(phox) PX domain of NADPH oxidase targets cell membrane via moesin-mediated association with the actin cytoskeleton. $J$ Cell Biochem 2004;92:795-809

Zhan Y, Virbasius JV, Song X, Pomerleau DP, and Zhou W. The p40phox and p47phox PX domains of NADPH oxidase target cell membranes via direct and indirect recruitment by phosphoinositides. J Biol Chem 2002; 277:4512-8 